\title{
PENGARUH KUALITAS PELAYANAN, FASILITAS, DAN PERSEPSI HARGA TERHADAP KEPUASAN MAHASISWA PADA UNIVERSITAS SATYA NEGARA INDONESIA KAMPUS A
}

\author{
Agus Wahyono*) \& Nuraini \\ *)Dosen Tetap Program S1 Jurusan Manajemen Fakultas Ekonomi Universitas Satya Negara Indonesia
}

Email : agoeswahyono9@gmail.com, nurraynii.na@gmail.com

\begin{abstract}
ABSTRAK
Penelitian ini bertujuan untuk menganalisis bagaimana pengaruh kualitas pelayanan, fasilitas, dan persepsi harga terhadap kepuasan mahasiswa di Universitas Satya Negara Indonesia (USNI). Penelitian ini bersifat kuantitatif, metode pengumpulan data menggunakan data primer dan data sekunder. Populasi penelitian ini adalah mahasiswa Strata-1 dari fakultas perikanan dan ilmu kelautan, fakultas teknik, fakultas ilmu sosial dan ilmu politik, dan fakultas ekonomi yang aktif kuliah pada tahun 2019. Metode pengambilan sampel menggunakan metode probability sampling dan teknik pengambilan sampel dengan menggunakan metode simple random sampling. Penentuan sampel dengan rumus slovin dengan tingkat kesalahan 10\%. Responden pada penelitian ini berjumlah 116 mahasiswa. Metode analisis data yang digunakan adalah analisis linear berganda dengan menggunakan bantuan SPSS versi 22. Kesimpulan hasil penelitian ini ditemukan bahwa Kualitas Pelayanan (X1), Fasilitas (X2), dan Persepsi Harga (X3) secara simultan berpengaruh terhadap Kepuasan Mahasiswa (Y). Kualitas pelayanan dan fasilitas secara parsial tidak berpengaruh pada kepuasan mahasiswa, sedangkan persepsi harga secara parsial berpengaruh terhadap kepuasan mahasiswa. Dan kontribusi $R^{2}$ sebesar 54,5\% terhadap Kepuasan Mahasiswa (Y), sedangkan sisanya sebesar 45,5\% dijelaskan oleh faktor atau variabel lain yang tidak dijelaskan dalam penelitian ini.
\end{abstract}

\section{Pendahuluan}

Pada abad ke-21 merupakan peningkatan era globalisasi yaitu revolusi industri 4.0, salah satu cara yang untuk menghadapi revolusi industri 4.0 adalah dengan meningkatkan modal manusia (Human Capital). Untuk meningkatkan modal manusia (Human Capital) salah satu faktor yang perlu diperhatikan adalah pendidikan. Perguruan tinggi merupakan salah satu lembaga penyelenggara tertinggi penyedia jasa pendidikan dalam masyarakat, yang turut serta dalam mencerdaskan kehidupan bangsa. Perguruan tinggi swasta sekarang dihadapkan dengan persaingan yang ketat antar perguruan tinggi swasta lain dan perusahaan yang membuka perguruan tinggi.

Universitas Satya Negara Indonesia (USNI) merupakan salah satu perguruan tinggi yang juga berperan selama 30 tahun dalam menciptakan sumber daya manusia yang berkualitas. USNI memiliki peringkat B secara institusi, namun masih banyak hal yang perlu di kembangkan oleh pengelola USNI. Penelitian ini diharapkan dapat memberikan sumbangsih pemikiran tentang persepsi mahasiswa yang sedang belajar di Universitas Satya Negara. Sebelum melakukan penelitian penulis melakukan pra survey kepada 25 mahasiswa/i USNI guna mengetahui persepsi masalah yang dari kacamata mahasiswa yang berkaitan dengan pemasaran . Penulis menanyakan 
beberapa variabel yaitu kualitas pelayanan, fasilitas, dan persepsi harga yang hasilnya dapat dilihat pada tabel dibawah ini:

Tabel 1. Pra Survey Kepuasan Mahasiswa

\begin{tabular}{|l|l|l|l|l|}
\hline No & Variabel & Puas & Cukup & Tidak Puas \\
\hline 1. & Kualitas Pelayanan & $31 \%$ & $45 \%$ & $24 \%$ \\
\hline 2. & Fasilitas & $33 \%$ & $41 \%$ & $26 \%$ \\
\hline 3. & Persespsi Harga & $24 \%$ & $52 \%$ & $24 \%$ \\
\hline
\end{tabular}

Berdasarkan tabel di atas di temukan bahwa persepsi kepuasan mahasiswa perihal variabel kualitas pelayanan, fasilitas, dan persepsi harga yang dirasakan mahasiswa masih terdapat gap persepsi tingkat kepuasan mahasiswa. Hal ini dapat dilihat tingkat ketidak puasan dan kecukupan kepuasan mahasiswa sangat tinggi dibandingkan dengan jumlah mahasiswa yang puas. Kepuasan Mahasiswa berada pada kisaran 30\%. Yang artinya masih rendah sekali.

Fenomena penurunan jumlah mahasiswa menjadi pertanyaaan apakah hal ini juga di pengaruhi oleh persepsi mahasiswa untuk memilih kuliah di kampus USNI.

Gambar 1 Mahasiswa USNI Strata-1 2017-2019

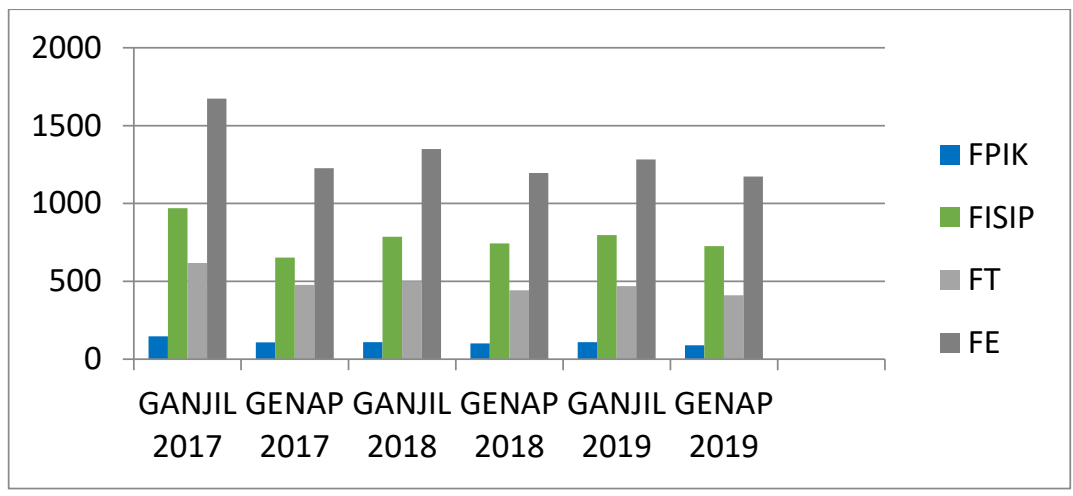

Sumber: Data Internal Kampus Diolah Penulis (2019)

Sebagai perguruan tinggi, Universitas Satya Negara Indonesia terus melakukan upaya persiapan dalam peningkatan kualitas pelayanan dan proses perkuliahan yang baik untuk masa depan Universitas Satya Negara Indonesia di dunia pendidikan dan menjadi salah satu Perguruan Tinggi Swasta terbaik. Menurut Tjiptono (2004: 59), kualitas pelayanan juga merupakan tingkat keunggulan dalam memenuhi keinginan konsumen. Beberapa penelitian (Ade, dkk, 2018) menyatakan bahwa faktor kepuasan dapat di pengaruhi oleh citra merek, kualitas pelayanan, dan persepsi harga. (Adie Kurbani, 2017) juga menyatakan dalam penelitiannya terdapat pengaruh kualitas layanan akademik dan fasilitas pendidikan pada kepuasan konsumen. Namun Putranto (2016) menyatakan sebaliknya bahwa kualitas pelayanan tidak berpengaruh terhadap kepuasan pelanggan. Umayya (2017) menyatakan fasilitas tidak berpengaruh terhadap kepuasan. Dan penelitian F.X. Sulistiyanto W.S dan Euis Soleha (2015) menyatakan bahwa persepsi harga tidak 
berpengaruh terhadap kepuasan pelanggan. Berdasarkan latar belakang serta adanya perbedaan penelitian sebelumnya mka penulis mengambil judul Pengaruh Kualitas Pelayanan, Fasilitas dan Persepsi Harga terhadap Kepuasan Mahasiswa di Universitas Satya Negara Indonesia.

\section{TINJAUAN PUSTAKA}

1. Kepuasan Mahasiswa

Menurut Philip Kotler dan Kevin Lane Keller (2009: 138) kepuasan (satisfaction) adalah perasaan senang atau kecewa seseorang yang timbul karena membandingkan kinerja yang dipersepsikan produk (atau hasil) terhadap ekspektasi mereka.

2. Kualitas Pelayanan (X1)

Menurut (Parasuraman, et., 1988) dalam Lupiyoadi (2018: 216) kualitas jasa dapat didefinisikan sebagai seberapa jauh perbedaan antara kenyataan dengan harapan pelanggan atas layanan yang mereka terima.

\section{Fasilitas (X2)}

Menurut Tjiptono (2011:11) pengertian fasilitas adalah merupakan segala sesuatu yang memudahkan konsumen dalam usaha yang bergerak dibidang jasa, maka segala fasilitas yang ada yaitu kondisi fasilitas, kelengkapan, desain interior, dan eksterior serta kebersihan fasilitas harus diperhatikan terutama yang berkaitan erat dengan apa yang dirasakan atau didapat konsumen secara langsung.

4. Persepsi Harga (X3)

Menurut Schiffman dan Kanuk (2004: 186), persepsi harga adalah pandangan atau persepsi mengenai harga bagaimana pelanggan memandang harga tertentu (tinggi, rendah, wajar) mempengaruhi pengaruh yang kuat terhadap maksud membeli.

\section{Kerangka Pemikiran Teoritis}

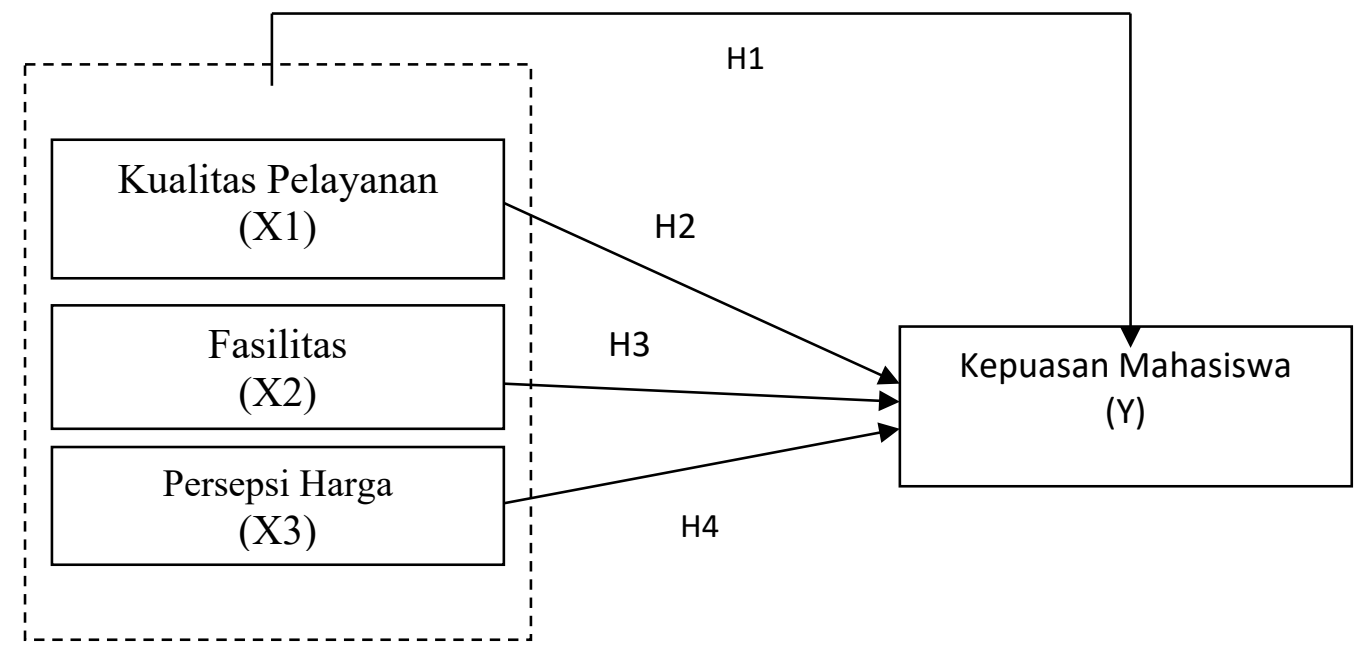

\section{Gambar 1. Kerangka Pemikiran Teoritis}


Selanjutnya maka dapat dirumuskan hipotesisnya sebagai berikut:

$\mathrm{H}_{1}=$ Pengaruh Kualitas Pelayanan $\left(\mathrm{X}_{1}\right)$, Fasilitas $\left(\mathrm{X}_{2}\right)$ dan Persepsi

Harga $\left(\mathrm{X}_{3}\right)$ terhadap Kepuasan Mahasiswa $(\mathrm{Y})$.

$\mathrm{H}_{2}=$ Pengaruh Kualitas Pelayanan $\left(\mathrm{X}_{1}\right)$ terhadap Kepuasan

Mahasiswa (Y).

$\mathrm{H}_{3}=$ Fasilitas $\left(\mathrm{X}_{2}\right)$ terhadap Kepuasan Mahasiswa $(\mathrm{Y})$.

$\mathrm{H}_{4}=$ Persepsi Harga $\left(\mathrm{X}_{3}\right)$ terhadap Kepuasan Mahasiswa (Y).

\section{METODOLOGI PENELITIAN}

Penelitian ini dilakukan di Universitas Satya Negara Indonesia pada kurun Januari 2019 hingga Mei 2019.

\section{Desain Penelitian \& Tekhnik Pengambilan Sampel}

Penelitian ini menggunakan penelitian hubungan kausal. Menurut Freddy Rangkuti (2017: 24) tujuan penelitian kausal yaitu mencari hubungan antara sebab dan akibat. Penelitian ini menggunakan metode kuantitatif. Metode kuantitatif menurut Sugiyono (2018: 7) disebut juga metode discovery, karena dengan metode ini dapat ditemukan dan dikembangkan berbagai iptek baru. Penelitian ini menggunakan kuesioner sebagai alat pengumpulan data, dan menggunakan analisis statistik yang akan diolah dengan menggunakan SPSS.

Variabel yang digunakan dalam penelitian ini adalah sebagai berikut:

1. Variabel terikat merupakan variabel yang dipengaruhi atau yang menjadi akibat, karena adanya variabel bebas. Sugiyono (2018: 39). Variabel Dependen: Kepuasan Mahasiswa.

2. Variabel bebas merupakan variabel yang mempengaruhi atau yang menjadi sebab perubahan atau timbulnya variabel dependen (terikat). Sugiyono (2018:39). Variabel Independen: Kualitas Pelayanan, Fasilitas, dan Persepsi Harga.

\section{Teknik Pengumpulan Data}

Teknik pengumpulan data pada penelitian ini adalah sebagai berikut:

1. Studi Kepustakaan

Penelitian kepustakaan dilakukan dengan cara mempelajari dan membaca buku-buku, literature-literatur serta bahan-bahan buku bacaan lainnya yang berhubungan dengan masalah yang diteliti, untuk memperoleh data teoritis yang relevan dengan pokok persoalan yang dibahas.

2. Kuesioner (Angket)

Metode kuesioner pada penelitian dilakukan dengan cara penyebaran pernyataan secara tertulis berupa kuesioner kepada mahasiswa/i Strata-1 Universitas Satya Negara Indonesia Kampus A. Pernyataan yang ada dalam kuesioner penelitian ini akan diukur dengan menggunakan skala likert. 


\section{Jenis Data Penelitian}

1. Data Primer

Merupakan data-data yang diperoleh langsung dari sumbernya. Data secara khusus dapat diambil dari individu atau perseorangan, seperti hasil wawancara atau hasil pengisisan kuesioner. Data primer yang artinya penulis langsung mendapatkan data dari kuesioner yang diisi oleh karyawan mahasiwa/i Universitas Satya Negara Indonesia yang dijadikan sampel dalam penelitian ini yang kemudian penulis olah data tersebut.

2. Data Sekunder

Data sekunder diperoleh dari studi kepustakaan, jurnal-jurnal penelitian yang berhubungan dan mendukung penelitian, internet, dan media lainnya.

\section{Populasi dan Sampel}

\section{Populasi}

Populasi dalam penelitian ini berjumlah 2.360 mahasiswa/i Strata-1 pada tahun akademik 2018/2019. yang disajikan dalam bentuk tabel sebagai berikut:

\section{Tabel 3.4}

\section{Populasi Mahasiswa USNI S-1 TA 2018/2019}

\begin{tabular}{|c|c|c|}
\hline No & Fakultas & Jumlah \\
\hline 1. & Ekonomi & 1.162 \\
\hline 2. & Fisip & 718 \\
\hline 3. & Teknik & 401 \\
\hline 4. & Ilmu Kelautan dan Perikanan & 79 \\
\hline & Total & 2.360 \\
\hline
\end{tabular}

Sumber: Data Sekunder Diolah (2019)

\section{Teknik Pengumpulan Sampel}

Penelitian ini menggunakan Probability Sampling. Teknik ini menggunakan Simple Random Sampling. Untuk menentukan ukuran sampel, penelitian ini menggunakan rumus Slovin dengan taraf kesalahan 10\%, dan diperoleh jumlah sampel 96 selanjutnya diambil secara acak tanpa memperhatikan fakultas, semester dan jenis kelamin. Pada penyebaran kusesioner diperoleh responden yang layak diteliti yaitu sebesar 116.

\section{HASIL \& PEMBAHASAN}

\section{UJI VALIDITAS \& UJI RELIABILITAS}

Hasil uji validitas ternyata semua item pertanyaan valid karena $r_{h i t u n g}>r_{\text {tabel }}$ dan hasil uji reliabilitas semua item variabel dinyatakan reliabel karena nilai Cronbach Alpha menunjukan $>$ 0,6 , maka semua variabel dikatakan reliabel. 
Tabel 3. Hasil Uji Reliabilitas

\begin{tabular}{|l|l|l|l|}
\hline Variabel & Cronbach's Alpha & Batasan & Keterangan \\
\hline Kualitas Pelayanan (X1) & 0,778 & $>0,6$ & Reliabel \\
\hline Fasilitas (X2) & 0,768 & $>0,6$ & Reliabel \\
\hline Persepsi Harga (X3) & 0,804 & $>0,6$ & Reliabel \\
\hline Kepuasan Mahasiswa (Y) & 0,782 & $>0,6$ & Reliabel \\
\hline
\end{tabular}

\section{Uji Asumsi Klasik}

Hasil Uji Normalitas

Tabel 4

Hasil Uji Normalitas -Kolmogrov Smirnov

One-Sample Kolmogorov-Smirnov Test

\begin{tabular}{|ll|r|}
\hline & & \multicolumn{1}{|c|}{$\begin{array}{c}\text { Unstandardized } \\
\text { Residual }\end{array}$} \\
\hline Normal Parameters & & 116 \\
& Mean &, 0000000 \\
Most Extreme Differences & Std. & 3,14256160 \\
& Deviation &, 053 \\
& Absolute &, 034 \\
Test Statistic & Positive &,- 053 \\
Asymp. Sig. (2-tailed) & Negative &, 053 \\
\hline
\end{tabular}

a. Test distribution is Normal.

b. Calculated from data.

c. Lilliefors Significance Correction.

$\mathrm{d}$. This is a lower bound of the true significance.

Sumber: Diolah Tahun 2019 dengan program SPSS versi 22

Nilai asymp. Sig. yang tertera adalah sebesar 0,200. Dengan demikian data yang digunakan dalam penelitian ini adalah berdistribusi normal, karena nilai sig. $>0,05$ yaitu $0,200>0,05$. 


\section{Uji Multikolinearitas}

Tabel 5

Hasil Uji Multikoliniearitas

Sumber: Diolah Tahun 2019 dengan program SPSS versi 22

Coefficients $^{\mathrm{a}}$

\begin{tabular}{|c|c|c|c|c|c|c|c|c|}
\hline \multirow{2}{*}{\multicolumn{2}{|c|}{ Model }} & \multicolumn{2}{|c|}{$\begin{array}{c}\text { Unstandardized } \\
\text { Coefficients }\end{array}$} & \multirow{2}{*}{$\begin{array}{c}\text { Standardized } \\
\text { Coefficients }\end{array}$} & \multirow[b]{2}{*}{$\mathrm{T}$} & \multirow[b]{2}{*}{ Sig. } & \multicolumn{2}{|c|}{ Collinearity Statistics } \\
\hline & & $\mathrm{B}$ & Std. Error & & & & Tolerance & VIF \\
\hline & (Constant) & 8,219 & 3,354 & & 2,450 &, 016 & & \\
\hline & Kualitas Pelayanan &,- 038 & 047 &,- 055 &,- 807 & ,421 & ,868 & 1,152 \\
\hline & Fasilitas &, 025 & 065 & 037 & ,382 & ,703 & ,438 & 2,282 \\
\hline & Persepsi Harga & 603 & 086 & 697 & 7,033 &, 000 & ,413 & 2,419 \\
\hline
\end{tabular}

a. Dependent Variable: Kepuasan Mahasiswa

Hasil uji multikolonieritas menunjukan variabel independen memiliki nilai Tolerance lebih dari 0,1 dan Variance Inflation Factor (VIF) lebih kecil dari 10. Maka dapat disimpulkan bahwa tidak ada multikolonieritas diantara variabel-variabel independen

\section{Uji Heteroskedastisitas}

\section{Gambar 2}

Hasil Uji Heteroskedastisitas dengan grafik Scatterplot

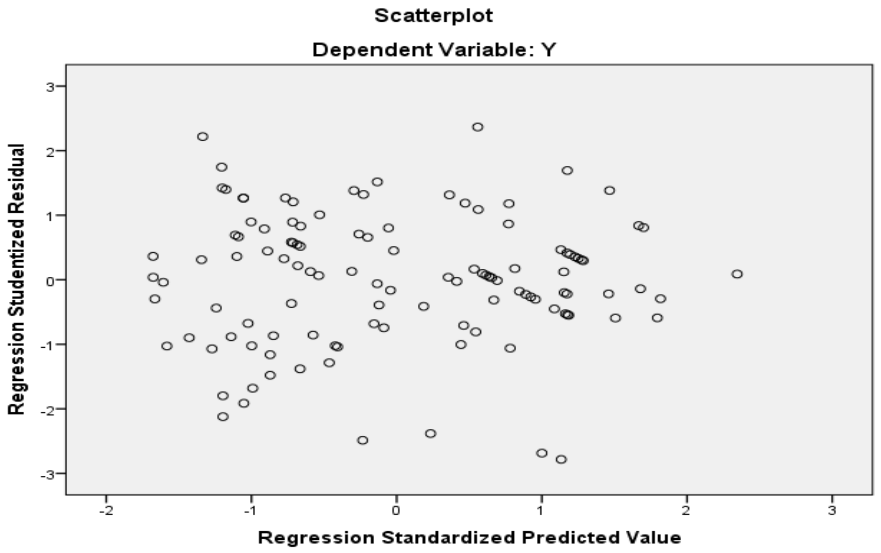

Sumber: Diolah Tahun 2019 dengan program SPSS versi 22

Dari gambar scatterplot di atas, dapat terlihat penyebaran titik-titik secara acak dan tidak menumpuk, serta membentuk suatu pola tertentu dengan pola penyebaran yang tidak jelas, baik di atas maupun di bawah angka 0 pada sumbu Y. Dengan demikian dapat disimpulkan bahwa tidak terjadi heteroskedastisitas pada penelitian ini, sehingga model regresi layak untuk digunakan dalam melakukan pengujian. 


\section{Uji Autokorelasi}

Tabel 7

Hasil Uji Autokorelasi

Model Summary ${ }^{b}$

\begin{tabular}{|l|r|r|r|r|r|}
\hline & & & & & \\
Model & $\mathrm{R}$ & R Square & Adjusted R Square & $\begin{array}{c}\text { Etd. Eror of the } \\
\text { Estimate }\end{array}$ & Durbin-Watson \\
\hline 1 &, $739^{\mathrm{a}}$ &, 545 &, 533 & 3,18437 & 1,388 \\
\hline
\end{tabular}

a. Predictors: (Constant), X3, X1, X2

b. Dependent Variable: Y

Sumber: Diolah Tahun 2019 dengan program SPSS versi 22

Dalam tabel ini menyatakan bahwa Durbin Watson sebesar 1,388. Menurut Danang Sunyoto (2016) hasil penelitian ini tidak terjadi Autokorelasi karena nilai DW nya berada diantara -2 dan 2 atau $-2<1,388<2$.

\section{HASIL UJI HIPOTESIS}

\section{Uji F}

Tabel 8

\section{Hasil Uji F}

ANOVA $^{\mathrm{a}}$

\begin{tabular}{|ll|r|r|r|r|r|}
\hline Model & & Sum of Squares & Df & Mean Square & F & \multicolumn{1}{c|}{ Sig. } \\
\hline 1 & Regression & 1362,502 & 3 & 454,167 & 44,789 &, $000^{\mathrm{b}}$ \\
& Residual & 1135,705 & 112 & 10,140 & & \\
& & & & & \\
& Total & 2498,207 & 115 & & & \\
\hline
\end{tabular}

a. Dependent Variable: Y

b. Predictors: (Constant), X3, X1, X2

Sumber: Diolah Tahun 2019 dengan program SPSS versi 22

Dari uji ANOVA (Analysis Of Varians) atau Uji F, menunjukan bahwa nilai Fhitung sebesar 44,789 dengan nilai signifikansi sebesar 0,000. Adapun nilai $F_{\text {tabel }}$ sebesar 2,68 yang didapat dari df $1=3$ dan $\mathrm{df} 2=116-3=113$. Karena signifikan $<0,05(0,00<0,05)$ dan nilai $F_{\text {hitung }}>F_{\text {tabel }}(44,789>2,68)$. Jadi Hipotesis pertama $\mathrm{H}_{\mathrm{a} 1}$ diterima, sehingga dapat disimpulkan Kualitas Pelayanan, Fasilitas dan Persepsi Harga berpengaruh secara signifikan terhadap Kepuasan Mahasiswa 


\section{Uji t}

Tabel 9

Hasil Uji t

\begin{tabular}{|l|l|l|l|l|}
\hline Variabel & $\begin{array}{l}\text { Koefisien } \\
\text { Regresi }\end{array}$ & T Hitung & Sig & Keterangan \\
\hline Konstanta & 8,219 & 2,450 &, 016 & \\
\hline Kualitas Pelayanan (X1) & $-0,221$ &,- 807 &, 421 & Signifikan \\
\hline Fasilitas (X2) & 0,540 &, 382 &, 703 & Signifikan \\
\hline Persepsi Harga (X3) & 0,737 & 7,033 &, 000 & Signifikan \\
\hline
\end{tabular}

Dependent Variable: Kepuasan Mahasiswa

Sumber: Data Primer Diolah (2019)

Berikut ini adalah hasil pengujian berdasarkan hipotesis:

a. Hasil Pengujian Hipotesis Kedua $\left(\mathrm{H}_{02}\right.$ dan $\left.\mathrm{H}_{\mathrm{a} 2}\right)$

Berdasarkan hasil uji $t$ pada variabel Kualitas Pelayanan, diperoleh $t_{\text {hitung }}$ sebesar $-0,807$ dengan tingkat signifikan sebesar 0,421. Karena tingkat signifikan yang dimiliki Kualitas Pelayanan $>0,05(0,421>0,05)$ dan nilai $t_{\text {hitung }}<t_{\text {tabel }}(-0,807<1,9813)$. Jadi hipotesis Kedua $\mathrm{H}_{02}$ diterima dan $\mathrm{H}_{\mathrm{a} 2}$ ditolak, sehingga dapat disimpulkan bahwa Kualitas Pelayanan tidak berpengaruh signifikan terhadap Kepuasan Mahasiswa.

b. Hasil Pengujian Hipotesis Ketiga $\left(\mathrm{H}_{03}\right.$ dan $\left.\mathrm{H}_{\mathrm{a} 3}\right)$

Berdasarkan hasil uji t pada variabel Fasilitas, diperoleh thitung sebesar 0,382 dengan tingkat signifikan sebesar 0,703 Karena tingkat signifikan yang dimiliki variabel Fasilitas $>0,05$ $(0,703>0,05)$ dan nilai $t_{\text {hitung }}<t_{\text {tabel }}(0,382<1,9813)$. Jadi hipotesis ketiga $\mathrm{H}_{03}$ diterima dan $\mathrm{H}_{\mathrm{a} 3}$ ditolak, sehingga dapat disimpulkan bahwa Fasilitas tidak berpengaruh signifikan terhadap Kepuasan Mahasiswa.

c. Hasil Pengujian Hipotesis Keempat $\left(\mathrm{H}_{04}\right.$ dan $\left.\mathrm{H}_{\mathrm{a} 4}\right)$

Berdasarkan hasil uji t pada variabel Persepsi Harga, diperoleh thitung sebesar 7,033 dengan tingkat signifikan sebesar 0,00 . Karena tingkat signifikan yang dimiliki Persepsi Harga $<0,05$ $(0,00<0,05)$ dan nilai $t_{\text {hitung }}>t_{\text {tabel }}(7,033>1,9813)$. Jadi hipotesis keempat $\mathrm{H}_{04}$ ditolak dan $\mathrm{H}_{\mathrm{a} 4}$ diterima, sehingga dapat disimpulkan bahwa variabel Persepsi Harga berpengaruh signifikan terhadap Kepuasan Mahasiswa

\section{Uji Regresi Linear Berganda}

Tabel 10

Hasil Analisis Regresi Linear Berganda

\begin{tabular}{|c|c|c|c|c|c|c|}
\hline & & \multicolumn{2}{|c|}{$\begin{array}{c}\text { Unstandardized } \\
\text { Coefficients }\end{array}$} & \multirow{2}{*}{$\begin{array}{c}\begin{array}{c}\text { Standardized } \\
\text { Coefficients }\end{array} \\
\text { Beta } \\
\end{array}$} & \multirow[b]{2}{*}{$\mathrm{T}$} & \multirow[b]{2}{*}{ Sig. } \\
\hline \multicolumn{2}{|c|}{ Model } & $\mathrm{B}$ & Std. Error & & & \\
\hline \multirow[t]{4}{*}{1} & (Constant) & 8,219 & 3,354 & & 2,450 &, 016 \\
\hline & Kualitas Pelayanan &,- 038 & ,047 &,- 055 &,- 807 & ,421 \\
\hline & Fasilitas &, 025 &, 065 & ,037 & ,382 & ,703 \\
\hline & Persepsi Harga & 603 & ,086 & 697 & 7,033 & , 000 \\
\hline
\end{tabular}


Berdasarkan hasil penelitian diperoleh persamaan regresi sebagai berikut:

$\mathrm{Y}=8,219+(-0,038 \mathrm{X} 1)+0,025 \mathrm{X} 2+0,603 \mathrm{X} 3$

Dari persamaan regresi linear berganda tersebut, arti dari angka-angka tersebut adalah sebagai berikut:

a. Diketahui nilai konstanta (a) sebesar 8,219. Itu berarti, apabila variabel independen dalam penelitian ini bernilai 0, maka Kepuasan Mahasiswa akan bernilai 8,219.

b. Nilai Koefisien Kualitas Pelayanan $\left(b_{1}\right)$ bernilai negatif sebesar -0,038. Artinya, apabila setiap Kualitas Pelayanan mengalami kenaikan sebesar 1 satuan, maka Kepuasan Mahasiswa akan mengalami peningkatan sebesar -0,038 satuan dengan asumsi variabel independen lainnya tetap.

c. Nilai Koefisien Fasilitas $\left(b_{2}\right)$ bernilai positif sebesar 0,025. Artinya, apabila setiap Fasilitas mengalami kenaikan sebesar 1 satuan, maka Kepuasan Mahasiswa akan mengalami peningkatan sebesar 0,025 satuan dengan asumsi variabel independen lainnya tetap.

d. Nilai Koefisien Persepsi Harga $\left(b_{3}\right)$ bernilai positif sebesar 0,603. Artinya, apabila setiap Persepsi Harga mengalami kenaikkan sebesar 1 satuan, maka Kepuasan Mahasiswa juga akan mengalami peningkatan sebesar 0,603 satuan dengan asumsi variabel lainnya tetap.

\section{Uji Koefisien Determinasi}

Pengujian ini bertujuan untuk mengukur seberapa jauh kemampuan model dalam menerangkan variasi variabel dependen. Di bawah ini merupakan hasil analisis determinasi:

Tabel 11

Hasil Uji Koefisien Determinasi

Model Summary ${ }^{\mathbf{b}}$
\begin{tabular}{|l|l|l|l|l|l|}
\hline & & & & & \\
Std. Error of the & & \\
Estimate & Adjusted R Square & Durbin-Watson \\
\hline 1 & $\mathrm{R}$ & R Square &, 533 & 3,18437 & 1,388 \\
\hline
\end{tabular}

a. Predictors: (Constant), X3, X1, X2

b. Dependent Variable: Y

Sumber: Diolah Tahun 2019 dengan program SPSS versi 22

Berdasarkan tabel 4.16 di atas, diketahui nilai Adjusted R Square yang dihasilkan sebesar 0,535 atau 53\%. Hal ini berarti bahwa sumbangan variabel Kualitas Pelayanan, Fasilitas, dan Persepsi Harga terhadap Kepuasan Mahasiswa sebesar 54,5\% dan sisanya sebesar 46,5\% (100\%-53,5\%) dijelaskan oleh variabel lainnya yang tidak dijelaskan dalam penelitian ini.

Berdasarkan tabel 4.16, nilai R (nilai korelasi) diperoleh sebesar 0,739. Artinya korelasi antara variabel kualitas pelayanan, fasilitas, dan persepsi harga terhadap kepuasan mahasiswa memiliki hubungan yang erat, karena nilainya mendekati 1 . 


\section{KESIMPULAN}

Penelitian ini bertujuan untuk meneliti dan memperoleh bukti mengenai Kualitas Pelayanan, Fasilitas, dan Persepsi Harga terhadap Kepuasan Mahasiswa. maka diperoleh kesimpulan sebagai berikut:

1. Secara simultan disimpulkan bahwa kualitas pelayanan, fasilitas dan persepsi harga berpengaruh secara signifikan terhadap kepuasan mahasiswa USNI Kampus A.

2. Secara parsial dapat disimpulkan bahwa kualitas pelayanan tidak berpengaruh signifikan terhadap kepuasan mahasiswa USNI Kampus A.

3. Secara parsial dapat disimpulkan bahwa fasilitas tidak berpengaruh signifikan terhadap kepuasan mahasiswa USNI Kampus A.

4. Secara parsial Persepsi dapat disimpulkan bahwa persepsi harga berpengaruh signifikan terhadap kepuasan mahasiswa USNI Kampus A.

\section{Daftar Pustaka}

Gozali, Imam. (2016). Aplikasi Analisis Multivariate Dengan Program (IBM SPSS). Edisi 8. Badan Penerbit Universitas Diponegoro. Semarang.

Juwandi, Hendy Irawan. (2004). Kepuasan Pelayanan Jasa. Erlangga. Jakarta.

Kotler, P., dan Keller, KL. (2008). Manajemen Pemasaran. Edisi 12. Jilid I dan II. PT. Indeks, PT Mancana Jaya Cemerlang, Jakarta.

Kotler, Phillip dan Armstrong. G. (2012). "Prinsip-prinsip Pemasaran”. Edisi 13 Jilid 1. Jakarta.

Lupiyoadi, Rambat dan Hamdani, A. (2001). Manajemen Pemasaran Jasa. Salemba Empat. Jakarta.

Lupiyoadi, Rambat. (2018). Manajemen Pemasaran Jasa: Berbasis Kompetensi Edisi 3. Salemba Empat, Jakarta.

Sugiyono. (2016). Metode penelitian Kuantitatif, Kualitatif $R \& D$ Cetakan ke-23, Alfabeta, Bandung.

Sugiyono. (2018). Metode penelitian Kuantitatif, Kualitatif $R \& D$ Cetakan ke-28, Alfabeta, Bandung.

Tjiptono, Fandy. (2015). Strategi Pemasaran. ANDI, Yogyakarta.

Sumber Jurnal:

Andari, C. L. S. (2017). Pengaruh kualitas pelayanan dan fasilitas terhadap kepuasan pengunjung studi pengunjung the sila's agrotourism.

Asri. (2019). Pengaruh Tax Avoidance dan Corporate Governance terhadap nilai perusahaan dengan manajemen laba sebagai pemoderasi.

Brillyan Jaya Sakti, Mahfudz. (2018). Analisis pengaruh kualitas layanan, ketepatan waktu pengiriman, dan fasilitas terhadap kepuasan pelanggan (Studi pada J\&T Express kota Semarang). ISSN (Online) 2337-3792, Semarang, 2018, hal 1-8.

Harjati, Lily, dan Venesia, Yurike. (2015). Pengaruh kualitas layanan dan persepsi harga terhadap kepuasan pelanggan pada maskapai penerbangan Tiger Air mandala.

Kurbani, Ardie. (2017). Pengaruh Kualitas Layanan Akademik dan Fasilitas Pendidikan terhadap Kepuasan Mahasiswa Kuliah pada Univeritas PGRI Palembang. Hal 22-35. 
Ningsih, Tri Martiani. L. (2018). Pengaruh kualitas pelayanan dan harga terhadap loyalitas pelanggan dengan kepuasan pelanggan sebagai variabel intervening pada PT.SUNGGONG LOGISTICS.

Nst, Ika Selvia Umayya. (2017). Pengaruh kualitas pelayanan, harga dan fasilitas terhadap kepuasan pasien pada klinik dokter gigi eka adhayani aksara Medan.

Permana, Ade Indra dkk. (2018). Pengaruh citra merek, kualitas pelayanan, dan persepsi harga terhadap kepuasan mahasiswa di Universitas Muhammadiyah Tangerang. Hal 121-143.

Putra, Frido Pratama. (2019). Pengaruh kualitas pelayanan, harga, dan lokasi terhadap kepuasan pelanggan biMBA-AIUEO BERDIKARI.

Putranto, T. A. W. A. (2016). Pengaruh kualitas pelayanan dan fasilitas terhadap kepuasan konsumen studi kasus pada konsumen PT. kereta api Indonesia daerah operasional di Yogyakarta. Ilmu dan riset manajemen. Hal 1-79.

Putri, Meilya Karya. (2018). Pengaruh kinerja dosen dan pelayanan administratif terhadap kepuasan mahasiswa pada Sekolah Tinggi Ilmu Ekonomi Indragiri (STIE-I) Rengat Kabupaten Indragiri Hulu. Halaman 1-148.

Sulistiyanto W.S, F.X, dan Soliha, Euis. (2015). Pengaruh persepsi harga, citra perusahaan, dan citra merek terhadap kepuasan dan loyalitas pelanggan pada apotek "Dela" di Semarang.

Wibowo, Ari Susanto. (2013). Pengaruh harga, kaulitas pelyanan, dan nilai pelanggan terhadap kepuasan konsumen pada rumah makan di kota Purwekerto. 